\title{
Neuroleptic Malignant Syndrome: Review, Diagnostic Critique
}

Khurram K. Durrani M.D.

Stanford University School of Medicine; Saint Elizabeths Residency Training Program, Washington, D.C.

Follow this and additional works at: https://jdc.jefferson.edu/jeffjpsychiatry

Part of the Psychiatry Commons

Let us know how access to this document benefits you

\section{Recommended Citation}

Durrani, Khurram K. M.D. (2002) "Neuroleptic Malignant Syndrome: Review, Diagnostic Critique," Jefferson Journal of Psychiatry. Vol. 17 : Iss. 1 , Article 3.

DOI: https://doi.org/10.29046/JJP.017.1.002

Available at: https://jdc.jefferson.edu/jeffjpsychiatry/vol17/iss $1 / 3$

This Article is brought to you for free and open access by the Jefferson Digital Commons. The Jefferson Digital Commons is a service of Thomas Jefferson University's Center for Teaching and Learning (CTL). The Commons is a showcase for Jefferson books and journals, peer-reviewed scholarly publications, unique historical collections from the University archives, and teaching tools. The Jefferson Digital Commons allows researchers and interested readers anywhere in the world to learn about and keep up to date with Jefferson scholarship. This article has been accepted for inclusion in Jefferson Journal of Psychiatry by an authorized administrator of the Jefferson Digital Commons. For more information, please contact: JeffersonDigitalCommons@jefferson.edu. 


\title{
Neuroleptic Malignant Syndrome: Review, Diagnostic Critique
}

\author{
Khurram K. Durrani, M.D. ${ }^{1}$
}

\begin{abstract}
Neuroleptic malignant syndrome (NMS) can be defined as an idiosyncratic and potentially fatal reaction to neuroleptic agents that consists of fever, mental status changes, muscle rigidity, autonomic dysfunction, respiratory distress and rhabdomyolysis. The pathogenesis of NMS is still not fully understood. The diagnosis presents a challenge and the diagnostic criteria need further refinement. The presentation and course of NMS are quite variable and can range from a progressive, fulminating, downhill course to a relatively benign and self-limiting course. Despite great improvements in the management of the syndrome, prevention and early diagnosis are the most important aspects of treatment.

\section{HISTORICAL BACKGROUND}

Although iatrogenic disorders of thermoregulation were reported soon after the introduction of phenothiazines, it was not until trials of haloperidol were conducted (1968) by Delay et al (1) that NMS was identified as a distinct complication of neuroleptic treatment. They named the cluster of adverse effects they observed in some patients on antipsychotics as NMS (2). This was partly related to the resemblance of this disorder to a type of neuroautonomic decompensation known as "syndrome malin" in France, which accompanied the terminal phases of infectious diseases and other illness affecting brain function (2,3). Except for some unique case reports and with the exception of work in France and Japan which confirmed the observations earlier made by Delay and Deniker, NMS remained virtually unknown to the medical word (4-7). After 1980, however, increasing recognition of NMS resulted in the publication of hundreds of case reports and numerous reviews $(8,9)$.
\end{abstract}

\section{EPIDEMIOLOGY}

The exact frequency of NMS is unknown. A number of retrospective and prospective studies have found between $0.02 \%$ and $1.9 \%$ of patients treated with neuroleptics to be affected with NMS (10). Several factors probably account for this

\footnotetext{
${ }^{1}$ Khurram K. Durrani, M.D. is currently a Child Psychiatry Fellow at Stanford Univ. School of Med. However, at the time of preparation of this manuscript he was an adult psychiatry resident at Saint Elizabeths Residency Training Program in Washington, DC.

Correspendence: Khurram K. Durrani, M.D., Stanford Univ. Sch of Med., Department of Psychiatry, 401 Quarry Rd., Stanford, CA 94305. EMAIL: kkddr@aol.com., (650) 724-3374 X8
} 
large difference, including differences in diagnostic criteria, survey techniques, patient populations, clinical settings and treatment practices (9).

\section{RISK FACTORS}

A number of studies have attempted to isolate possible risk factors for the development of NMS. A prior episode of NMS appears to predispose to subsequent episodes. Similarly the longer the time elapsed after an episode of NMS, the lower the risk of recurrence of NMS (11). NMS is found primarily in young and middle-aged adults. Though the very young and the elderly are more susceptible, the incidence of NMS in this population segment is low as neuroleptics are used less frequently and in lower doses in these patients. Parallel with the use of neuroleptics, the mean age is estimated to be 40 years. The syndrome appears to have a predilection for young men between $16-44$ years of age. In one case control study, age did not distinguish patients with NMS from controls (12). NMS occurs independently of climate and ambient temperature. Although high temperatures and humidity may augment the risk of NMS, they need not be present for NMS to occur. Occasionally, heredity has been implicated in the causation of NMS $(13,14)$. However, the general consensus is otherwise. Though the molecular basis of NMS is unclear, some recent studies from Japan suggest that genetic factors are involved in its pathogenesis (15). Considering possible involvement of the Serotonergic system in NMS, the associations between NMS and polymorphisms of $5-\mathrm{HT}_{1 \mathrm{~A}}$ and $5-\mathrm{HT}_{2 \mathrm{~A}}$ receptor genes were studied. However, researchers were unable to conclude that polymorphisms in $5-\mathrm{HT}_{1 \mathrm{~A}}$ and $5-\mathrm{HT}_{2 \mathrm{~A}}$ are factors determining susceptibility to NMS. Another study from Japan failed to show any significant relationship between cytochrome P450, subtype 2D6 (CYP 2D6) genotypes (reported to be associated with susceptibility to Parkinson's disease and multi system atrophy) and the possible susceptibility to NMS and sub-acute myelo-optico-neuropathy (16).

NMS is not specific to any neuropsychiatric diagnosis $(8,9)$. However, various authors have proposed that patients with mood disorders, catatonia, schizophrenia or organic syndromes may be at risk $(9,17-19)$. Systemic risk factors have included exhaustion, psychomotor activity and dehydration. Besides psychomotor agitation, other psychopathological features such as confusion, disorganized behavior and catatonia may be risk factors for NMS. It has also been found that NMS patients are significantly more agitated prior to the onset of NMS.

\section{OTHER RISK FACTORS}

Various other studies have found that previous electroconvulsive therapy (ECT), HIV infection, history of dementia, learning disabilities, advanced cancer, severe malnutrition, severe stress after multiple fractures, burns and postpartum period are additional risk factors for the development of NMS. All these risk factors are in 
TABLE A.

\section{Clinical Classification of Neuroleptics}

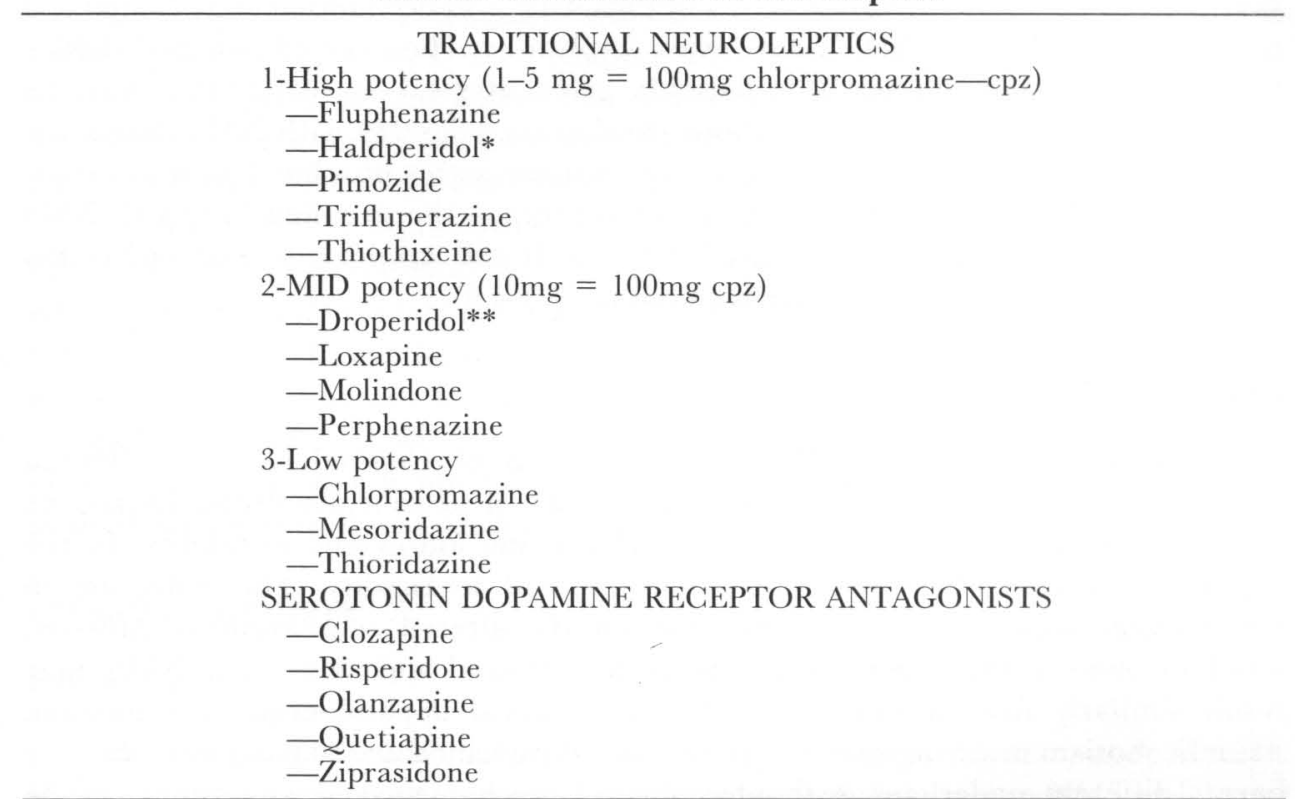

*IV route/should be avoided.

**Only available neuroleptic that can be given by IV route.

addition to the pharmacologic risk factors and extrapyramidal signs (as discussed under clinical features) including akathisia $(9,12,20)$.

\section{PHARMACOLOGIC RISK FACTORS AND VARIABLES}

Virtually all classes of Dopamine antagonists have been associated with NMS and NMS-like syndromes. This includes not only the typical (traditional) and atypical (Serotonin Dopamine Antagonists-SDA's), but also agents like prochlorperazine, promethazine, metoclorpramide, tegretol, lithium, methylphenidate, various antidepressants and anesthetics. Table A shows the general clinical classification of traditional neuroleptics and a list of currently available SDA's. According to some studies, about $17 \%$ of NMS patients experienced a similar episode during prior treatment with neuroleptics. Likewise, 30\% developed subsequent episodes on rechallenge with neuroleptics. Haloperidol has been implicated in nearly half of the reported cases. NMS is not usually the result of overdosage and occurs in dosages within therapeutic range (21). Some studies found that high potency agents increase the risk of NMS, whereas other studies either do not support, or even contradict, these findings (11,21-23). Similarly, a number of studies have observed that the 
loading rate of neuroleptics, rather than the total dosage (a potential hazard of rapid neuroleptization) is a key risk factor. However other studies have contradicted the same $(11,12,24)$. NMS or NMS like syndromes have also been observed with atypical neuroleptics as well. All SDA's have been implicated. However, Hasan and Bukley reported that NMS can occur in-patients given atypical antipsychotics, but the side-effect profiles of these medications overlap considerably with NMS diagnostic criteria. Atypical antipsychotics may cause neurotoxicities unrelated to (but misattributed to) NMS (25). Currently, the very existence of the so-called "atypical" NMS with SDA's is being actively debated, with both the proponents and opponents justifying their claims with supportive findings (25-29).

\section{PATHOGENESIS}

Evidence indicates that NMS is a distinct form of drug-induced hyperthermia that is related to dopamine antagonist properties of neuroleptic drugs. Dopamine reduction in the hypothalamus may cause fever and autonomic instability. In the nigrostrial system, dopamine reduction may lead to rigidity. The reduction in corticolimbic dopamine activity may explain the altered consciousness. Mutism, which involves severe hypomotility, diminished arousal and akinesia in NMS, may result similarly from alteration in the mesocortical dopaminergic transmission. Akinetic mutism involving severe hypomotility, diminished arousal and mutism, may have a different underlying pathophysiological mechanism and sometimes can be clinically difficult to distinguish from psychogenic catatonia and NMS (30).

Dopaminergic influences on autonomic regulatory mechanisms may be mediated by peripheral dopamine receptors. Although central dopaminergic hypofunction seems the most likely cause of rigidity and tremor, peripheral mechanisms may give rise to other features of the syndrome. The debate continues over whether the heat-generating hypermetabolism of muscle in NMS is centrally or peripherally mediated. The beneficial effect of dantrolene, a skeletal muscle relaxant, in reducing the duration of the syndrome supports the peripheral mechanism. However, the beneficial effects of centrally acting medications points towards a central mechanism (31).

A number of investigators have proposed various other neurotransmitter abnormalities including sertonergic hyperfunction, excessive catecholamine secretion, gamma-amino butyric acid deficiency, norepinephrine/dopamine imbalance and serotonin/dopamine imbalance. Others have implicated $\mathrm{Ca}^{2+}$ which in addition to functioning as a second messenger in its own right, is involved in mechanisms related to cyclic adenosine monophosphate $\left({ }_{\mathrm{C}} \mathrm{AMP}\right)$ and phosphoinositide second messenger systems $(9,32,33)$. According to the universal field hypothesis of catatonia and NMS (which in fact is an expansion of Lauterbach's theory of catatonia), catatonia and NMS are etiologically not divergent entities (34). According to this hypothesis the two syndromes are a single entity that result from variable combination of: low gamma aminobutyric acid (GABA) activity at $\mathrm{GABA}_{\mathrm{A}}$ receptor; high $5-\mathrm{HT}_{1 \mathrm{~A}}$ recep- 
tor activity; low dopamine at $\mathrm{D}_{2}$ receptor and low glutamate activity at $\mathrm{N}$-methylD-aspartate (NDMA) receptor.

Recently a pathophysiological model has been proposed for NMS according to which a predisposition to extreme sympathetic nervous system activity in response to emotional or psychological stress may constitute a trait vulnerability for the syndrome. This vulnerability, when coupled with state variables such as acute psychic insult or dopamine antagonism, could lead to the genesis of NMS (35).

As we can see the exact pathophysiological mechanism of NMS remains unclear. Caroff and Mann have found that lesions involving the hypothalamus, other areas adjacent to the third ventricle, the anterior cingulate cortex and the brain stem have resulted in NMS-like conditions (36). There is paucity in literature about conclusive neuroanatomical findings in patients with NMS. Postmortem findings are either nonspecific or inconsistent. Autopsy findings have included cerebellar degeneration, necrosis of hypothalamic nuclei, cell loss in the nucleus basalis (in lethal catatonia treated with neuroleptics), ischemic/anoxic changes, or no changes at all (37-41).

\section{CLINICAL FEATURES}

\section{Prodromal Signs}

Identification of prodromal signs could be useful in aborting an episode of NMS. However, these signs are nonspecific, do not necessarily progress to NMS and do not always precede the syndrome. Prior to the onset of a full-blown syndrome, insidious neurologic and autonomic signs can occur and not only defy diagnosis but may also prove resistant to conventional treatment. Specific prodromal signs may include unexpected changes in mental states, dysarthria, dysphagia, diaphoresis, sialorrhea, incontinence or low grade temperature elevations, rigidity, myoclonus, tremor or other extrapyramidal signs that are unresponsive to antiparkinsonian agents.

\section{Clinical Signs}

The classical NMS patient is alert but appears dazed and mute. For the psychiatrist, the most suggestive features are fluctuating consciousness (ranging from confusion to even coma), labile vital signs (tachycardia, unstable or elevated blood pressure), laboratory evidence of muscle injury (elevation of creatine kinaseCK, aldolase, serum myoglobin) and leukocytosis. Other features include diaphoresis, dysphagia, tremor, incontinence, and mutism. Extreme hyperthermia may predispose to complications such as, irreversible cerebellar or other brain damage, if not reduced immediately $(8,42)$. Muscle rigidity is usually of generalized type, which may be lead-pipe type (more often) or cogwheel type (less frequently). Moderate to severe respiratory distress and tachypnea, which may result from metabolic acidosis, hyperthermia, chest wall restriction, aspiration pneumonia, or pulmonary emboli may be observed $(19,43)$. 


\section{Laboratory Findings}

There are no specific or pathognomonic lab tests for NMS. Complete lab evaluation is essential in excluding other causes of the syndrome and identifying complications. Elevated CK, elevated serum myoglobin levels, myoglobinuria and rhabdomyolysis may progress to renal failure. Other elevated enzymes include lactate dehydrogenase (LDH), transaminases and aldolase. Leukocytosis, with or without left shift, is a common occurrence, which may generate further confusion about the etiology, as it can also suggest acute bacterial infection. Metabolic acidosis and hypoxia are other common findings. Less consistent findings include hyponatremia, hypernatremia, low serum iron, elevated catecholamines and coagulopathies. Cerebrospinal fluid examination is usually negative, but may show elevated protein occasionally. Non-focal, generalized slowing on electroencephalography has been reported in $54 \%$ of cases $(8,9,41,43)$.

\section{DIFFERENTIAL DIAGNOSIS}

The differential diagnosis of NMS, which encompasses a broad range of disorders, can be challenging. The clinician suspecting NMS should carefully rule out other possible causes first. This may necessitate a thorough medical and neurological evaluation. Table $\mathrm{B}$ enumerates the most important conditions likely to be confused with NMS. From a psychiatric standpoint, serotonin syndrome and catatonia are the most important differential diagnoses (Table G \& D). Briefly, however, because of the historical significance, anticholinergic intoxication and malignant hyperthermia are also addressed.

\section{Anticholinergic Intoxication}

There is some resemblance between anticholinergic intoxication and incomplete varieties of NMS. Anticholinergic intoxication causes fever, autonomic instability and altered consciousness. The mentioned below, traditional mnemonic for atropine toxicity captures both the predictable and unpredictable antimuscarinic effects.

$>$ Hot as hare

> Blind as a bat

$>$ Red as a beet

$>$ Mad as a hatter

$>$ Dry as a bone

Confusing NMS with acute dystonias, akathisia and the parkinson syndrome and treating it with anticholinergics can further complicate the clinical picture.

\section{Malignant Hyperthermia}

Malignant hyperthermia (MH) was first clearly reported in 1960 by Denborough and Lovell (45). These authors presented a family in which 10 patients 
TABLE B.

Differential Diagnosis of NMS

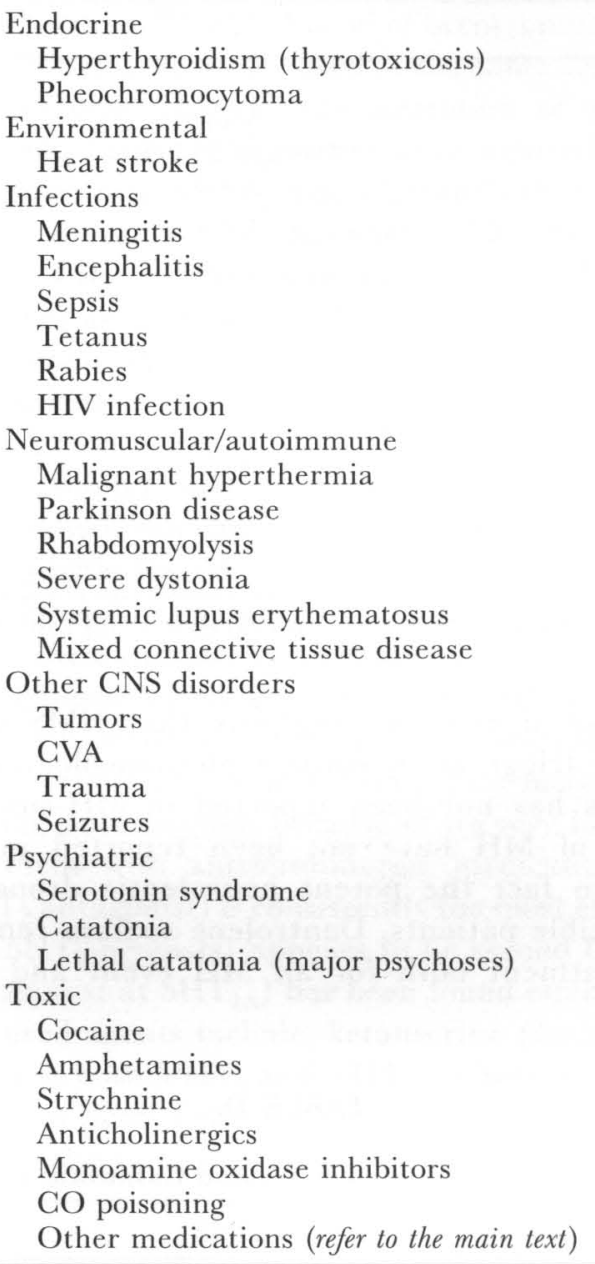

had died while undergoing anesthesia. Subsequent reports established that there was an inherited basis to the syndrome. $\mathrm{MH}$ is more common in males and is estimated to occur in 1 in 15,000 pediatric and 1 in 50,000-100,000 adult anesthetic procedures $(46-49)$. $\mathrm{MH}$ is a hypermetabolic syndrome in which muscular rigidity, temperature elevation and metabolic acidosis occur in response to an anesthetic agent as well as to depolarizing muscle relaxants. Halothane, Isoflurane, Trichloroethlene, Diethylether, Succinylcholine, Enflurane, Methoxyflurane, Chloroform, Cyclopropane and Ketamine have all been 
TABLE C.

Differentiating Characteristics of NMS and SS

\begin{tabular}{lcc}
\hline & S S & NMS \\
\hline Symptoms/signs & & \\
Onset & Acute & Gradual \\
Resolution & Average 24 hours & Average 9 days \\
Hyperreflexia & +++ & + \\
Myoclonus & +++ & + \\
Laboratory findings & + & +++ \\
$\quad$ Leukocytosis & + & +++ \\
CPK & + & ++ \\
Transaminases & No & Yes \\
Cause & Yes & No \\
Dopamine antagonists & & ++ \\
Serotonin agonists & 0 & 0 \\
Treatment & + & ++ \\
Dopamine agonists & + & + \\
Serotonin antagonists & &
\end{tabular}

Key: $+=$ Slight $++=$ moderate $+++=$ marked; $0=$ no role in treatment .

implicated (46). Clinical evidence suggests that NMS and $\mathrm{MH}$ are distinct entities and probably triggered by distinct pharmacological mechanisms. Sensitivity to neuroleptics has not been reported in $\mathrm{MH}$-susceptible patients and conversely episodes of MH have not been reported in patients with NMS during anesthesia. In fact the potent neuroleptic droperidol has been used safely in MH-susceptible patients. Dantrolene sodium remains the mainstay of pharmacological treatment both for an $\mathrm{MH}$ event and as treatment before surgery.

TABLE D.

Differentiating Characteristic of NMS and Catatonia (Common Variety)

\begin{tabular}{ccc}
\hline & NMS & Catatonia \\
\hline Clinical signs & & \\
Hyperthermia & +++ & + \\
Motor rigidity & $++/+++$ & ++ \\
Mutism & ++ & ++ \\
Autonomic & ++++ & ++ \\
instability & +++ & ++ \\
Laboratory findings & +++ & + \\
$\quad$ Elevated CPK & ++ & \pm \\
Leukocytosis & Myoglobinuria & ++
\end{tabular}




\section{Serotonin Syndrome}

Serotonin syndrome (SS) is a potentially life-threatening complication of psychopharmacologic drug therapy. The likelihood of occurrence increases if two drugs that affect brainstem serotonin levels are used at the same time. The syndrome can occur within minutes of dose change, administration of a new agent or, less frequently, may take weeks to occur. SS is often unrecognized because of the varied and nonspecific nature of its symptomatology. Currently there is no formal diagnostic criteria for SS. The syndrome may be characterized by alteration in cognition and behavior, jerking spasm of the muscles, increased reflexes, diarrhea, dilated pupils (which may be unreactive) and myoclonus. Meperidine and dextromethorphan are potent inhibitors of serotonin uptake and are notorious for precipitating acute SS, especially in patients taking MAOI's (monoamine oxidase inhibitors) including selegiline (50,51). Selegline is used as adjunctive therapy in Parkinson's diseases because of its ability to inhibit MAO-B isoenzymes. However, this selectivity in MAO-B inhibition is lost with dosages that are higher than the usual therapeutic range. Data are not available for the reversible inhibitors of monoamine oxidase (RIMA's). In addition, dopamine agonists (e.g. levodopa), direct serotonin receptor agonists (e.g. amphetamines, cocaine, etc) all have the potential to cause SS. By a poorly understood mechanism, electroconvulsive therapy (ECT) can also increase serotonin activity. In mild to moderate cases the syndrome will resolve within 24-72 hours with discontinuation of all medications that may increase serotonin concentration (Fluoxetine being an exception because of its very long half life). In more severe varieties, treatment with antiserotonergic medications may be required. Cyproheptadine (a $5 \mathrm{HT}_{2}$ antagonist) is consistently the most effective agent (52-54). Methysergide (partial $5 \mathrm{HT}_{2}$ agonists) appears to be second best $(55,56)$. As a sole agent, propanolol (antagonist at $5 \mathrm{HT}_{1 \mathrm{~A}}$ ) has been found effective in very few cases. Other less frequently used agents include, ketanserine (antagonist at 5-HT2) and mirtazapine (antagonist at both $5-\mathrm{HT}_{3}$ and $5-\mathrm{HT}_{2}$ ). There are a number of features in common between SS and NMS. Table C shows some important differences, though most of them are not absolute.

\section{Catatonia}

Catatonia is a clinical syndrome characterized by bizarre motor activity and psychosis. The essential nature of catatonia is controversial. The syndrome may be characterized by features like mutism, stupor, catalepsy, waxy flexibility, gegenhalten, stereotypy, echophenomena, automatic obedience etc. Although people with catatonia appear unaware of their surroundings, upon recovery, catatonic patients can usually give a complete report of the events that went on during their stupor. Recent research suggests that catatonia is more closely associated with affective disorders than with psychotic disorders. In DSM-IV-TR catatonia is classified both under general medical condition and as a subtype of schizophrenia. Also, it is 
included as a cross-sectional symptom feature under mood disorders. NMS is especially difficult to differentiate from catatonia. Both syndromes present with bizarre motor activity and fever, in addition to an altered mental status. Furthermore, many patients who developed catatonia have already been treated with antipsychotic medication making it difficult to differentiate their cases from that of patients with NMS. According to some reports, preexisting catatonia in a patient constitutes a significant risk factor and treating such patients with antipsychotics may facilitate the progression of a benign catatonia to a more fulminant NMS-like malignant syndrome $(18,57)$. Comparison shown in Table D can assist the clinician in establishing an appropriate diagnosis. Treatment of catatonia ranges from supportive care to pharmacologic interventions like benzodizapines, TSH and TRH to procedures like ECT.

\section{DIAGNOSTIC CRITERIA FOR NMS-CRITIQUE PLUS PROPOSED CHANGES IN $D S M-I V-T R$}

NMS is a rare and serious complication of medication therapy. An incorrect diagnosis or a delay in diagnosis will further increase morbidity and mortality. The first step in effective management requires early recognition/diagnosis of the syndrome. In early mild cases NMS may not be malignant at all.

Like its prevalence and management, this comparatively recent phenomenon has generated considerable controversy with regard to its diagnostic criteria. The waters are muddied still further with the increased recognition of milder or incomplete varieties (forms frustes). Some authors believe that NMS is at one end of a range of effects induced by neuroleptics, such as parkinsonism or dystonia, others believe that the term should be reserved only for a full-blown syndrome which has the features of an idiosyncratic reaction more akin to malignant hyperpyrexia $(58,59)$. This debate on the diagnostic criteria has crucial implications for the management of NMS. Consensus generally exists about managing the full-blown typical syndrome. However, management of mild, early, incomplete (or the so-called atypical varieties), and when the cause is not a neuroleptic gives rise to a number of important questions and lacks consensus. Although the diagnosis of NMS is made after excluding other causes of the patient's signs and symptoms, it is not always a simple task. At least 5 sets of diagnostic criteria of NMS have been published.

In 1980, Caroff published a review of 60 cases from the world literature, summarizing the clinical features and course of NMS and highlighting the nonspecificity of the clinical syndrome which could be associated with other drugs and diseases (8) (Table E) (42). Levenson in 1985 suggested a diagnostic criteria for NMS involving major and minor manifestations (60). (Table F). This was followed by the diagnostic criteria proposed by Pope et al, 1986 (61) (Table G). Consistent reporting of the constellation of clinical and laboratory features, enabled several groups to propose the Operational diagnostic criteria for NMS (Table H) (62). Because of lack of consensus, in 1994 the American Psychiatric Association came forward with the 
TABLE E.

\section{Criteria for NMS}

\section{Caroff SN, Mann SC, Lazarus A, et al NMS criteria*}

1. Treatment with neuroleptics within 7 days of onset (2 to 4 weeks for depot neuroleptics)

2. Hyperthermia $\left(>38^{\circ} \mathrm{C}\right)$

3. Muscle rigidity

4. Five of the following:

Change in mental status

Tachycardia

Hypertension or hypotension

Tachypnea or hypoxia

Diaphoresis or sialorrhea

Tremor

Incontinence

Creatinine phosphokinase elevation or myoglobinuria

Leukocytosis

Metabolic acidosis

5. Exclusion of other drug-induced, systemic, or neuropsychiatric illnesses

*All five items required concurrently.

DSM-IV research criteria on NMS. DSM-IV \& DSM-IV-TR (text revision) invites input and commentary from researchers and clinicians for refinement of the criteria. Currently, there is insufficient information to warrant inclusion of the criteria as an official category in DSM-IV-TR and thus it is placed in Appendix B of the manual (Table I) (63).

Although it is generally said that the DSM-IV-TR criteria are broader than earlier diagnostic criteria, at times this writer, in his experience with four patients, found DSM-IV-TR too restrictive and narrow. Severe rigidity. The criterion A of

TABLE F.

\section{Levenson Criteria for NMS*}

\begin{tabular}{l}
\hline Major criteria \\
-Fever \\
- Rigidity \\
-Elevated CK \\
Minor criteria \\
- Tachycardia \\
-Abnormal blood pressure \\
- Tachypnea \\
-Altered mental status \\
-Diaphoresis \\
- Leukocytosis
\end{tabular}

*To make the diagnosis of NMS three major or two major and four minor manifestation must be present as well as history of neuroleptic use. 


\section{TABLE G.}

\section{Diagnostic Criteria for NMS}

*Pope and coworkers criteria for NMS

1. Oral temperature of at least $38^{\circ} \mathrm{C}$ in the absence of another known cause

2. At least two extrapyramidal side effects from the following list:

Lead pipe-type muscle rigidity, cogwheeling, sialorrhea, oculogyric crisis, retrocollis, opisthotonos, trismus, dysphagia, choreiform movements, dyskinetic movements, festinating gait, and flexor-extensor posturing.

3. Autonomic dysfunction characterized by two or more of the following: Hypertension, tachycardia, tachypenea, prominent diaphoresis, and incontinence.

*Requires all three items for a definite diagnosis.

DSM-IV-TR research criteria 333.92 further qualifies "rigidity" as "severe" - a qualification not used by any of the previous criteria. Mr. A (a 48 year old male with the diagnosis of chronic schizophrenia), on traditional neuroleptics, including a recent shot of $100 \mathrm{mg}$ Haldol decanoate, had mild to moderate CPK elevations $\geqslant 1100-1400 \mathrm{iu} / \mathrm{ml}$, along with symptoms and signs and laboratory evidence of NMS), but did not develop severe muscle rigidity during the entire 10-12 day course of the syndrome. The same patient, who was treated with both general and standard specific intervention (as discussed in the treatment section), could not have been labeled as NMS by the DSM-IV-TR criteria but was diagnosed as NMS by all other earlier diagnostic criteria. Adhering strictly to DSM-IV-TR research criteria 333.92 could have not only delayed the important diagnosis but also affected the very essential early intervention. Fever. MR. B (a 37 years old male with diagnosis of chronic schizoaffective disorder, on both traditional and atypical neuroleptics, (Hal-

TABLE H.

\section{Operational Criteria for Diagnosis of NMS}

The following three items are all required for a diagnosis:

1. Hyperthermia: oral temperature of at least $38^{\circ} \mathrm{C}$ in the absence of another known cause.

2. Severe extrapyramidal effects characterized by two or more of the following: leadpipe muscle rigidity, pronounced cogwheeling, sialorrhea, oculogyric crisis, retrocollis, opisthotonos, trismus, dysphagia, choreiform movements, festinating gait, and flexorextensor posturing.

3. Autonomic dysfunction characterized by two or more of the following: hypertension (at least 20-mm rise in diastolic pressure above baseline), tachycardia (at least 30 beats/minute), prominent diaphoresis, and incontinence.

In retrospective diagnosis, if one of those three items has been specifically documented, a probable diagnosis is still permitted if the remaining two criteria are clearly met and the patient displays one of the following characteristic signs: clouded consciousness as evidenced by delirium, stupor, or coma: leukocytosis (more than 15,000 white blood cells/MM): and serum creatinine kinase level greater than 1,000 IU/ML. 
TABLE I.

DSM-IV-TR Research Criteria (333.92)

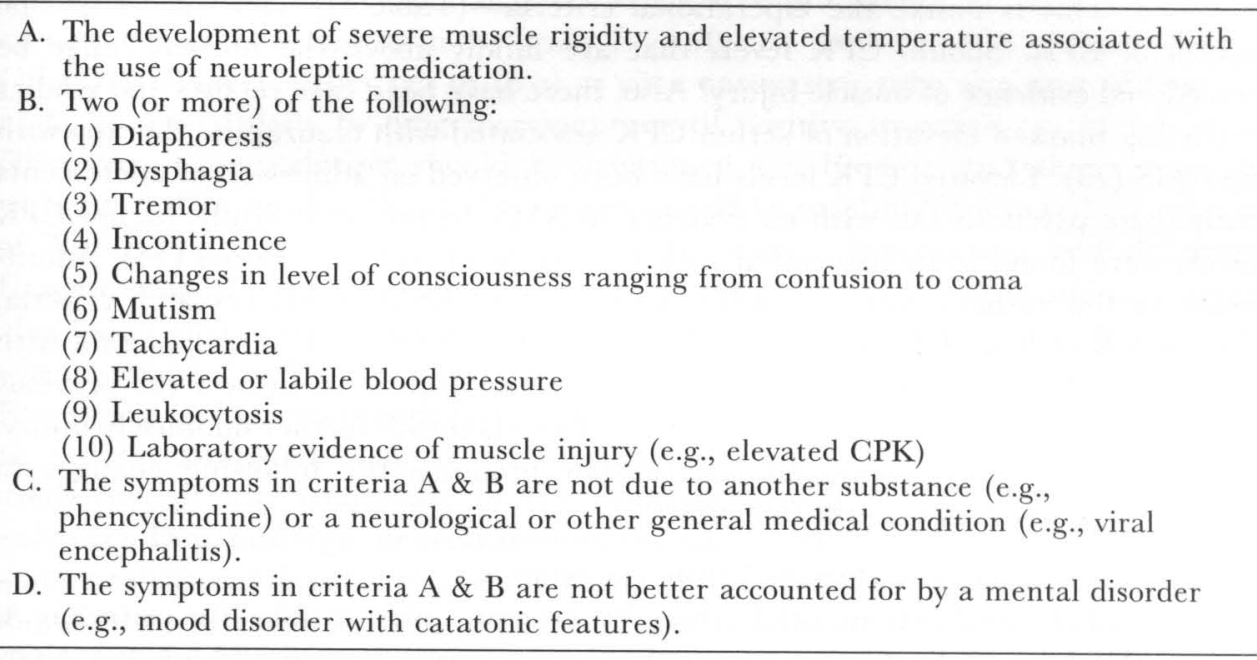

dol 10mg qd and Zyprexa 10mg qd), plus Paxil 20mg qd and nizatidine 150mg qhs for acid dyspepsia presented to the ER with all the typical features of the syndrome including severe muscle rigidity but with no fever. Patient remained afebrile (max $99^{\circ} \mathrm{F}$-month June) for the next 72 hours but then developed temperature up to $102.5^{\circ} \mathrm{F}$. Here again, the patient could have not been initially diagnosed with NMS using the DSM-IV-TR criteria, but was diagnosed using the Levenson criteria and fulfilled therein the minimal requirement of two major and four minor manifestations. Earlier in 1995, a similar case has been reported by Baker R.W. et al (64). Recently, in another study of NMS among children and adolescents, six out of the sixty two subjects with NMS did not develop fever (23). History of neuroleptic use. Further review of criterion A of the DSM-IV-TR research criteria makes it very obvious that the history of neuroleptic use is a must for the diagnosis of the syndrome. However, there is abundant literature in the field which demonstrates that NMS is caused by medications and drugs other than "Neuroleptics." Examples include metoclopramide, prochlorperazine, promethazine, anesthetics, diphenydramine, disprophyllin, antidepressants (including SSRI's, amitriptyline, amoxapine), methylphenidate and street drugs like cocaine and 3,4-methylenedioxymethamphatmine (MDMA), etc (65-72). Should these syndromes, which at times are clinically indistinguishable from NMS, be called "NMS caused by other medications/drugs" or should the DSM-IV-TR criteria be broadened? In addition, we have already seen under pharmacologic risk factors and variables, the more atypical variants of NMS caused by SDA's and the debate they are generating (25-29). These syndromes do not always meet DSM-IV-TR research criteria but do meet Levenson's original (Table F) 
and Addonizio's modified criteria (29). CPK Elevation. DSM-IV-TR researchcriteria B (10) "elevated CPK"- does generate further confusion as no range is provided. This is unlike the Operational criteria-(Table $\mathrm{H}$ ) which gives specific values of CPK. Should CPK levels that are mildly above the normal range be considered evidence of muscle injury? Also, there have been case reports and studies reporting marked elevation of serum CPK associated with olanzapine therapy with no NMS (73). Elevated CPK levels have been observed on admission of adolescents with acute psychosis but with no evidence of NMS. In the same study, higher GPK levels were found to be associated with the use of physical restraints (74). Admittedly, in the authors opinion, unlike criterion A of DSM-IV-TR research criteria, criterion B (10) is of little value on its own and is to be used in conjunction with criterion A, C and D. However, it offers little or no improvement over the previous diagnostic criteria (Table $\mathrm{E}$ and $\mathrm{H}$ ) which in fact elaborate further on muscle injury. In view of the aforementioned, this author proposes the following changes in DSM-IV-TR research criteria (333.92).

1. Remove the term "severe" from criterion A.

2. Include medications other than "neuroleptic medications" in criterion A. (Various medications work on the dopaminergic system and are not pharmacologically classified as neuroleptics, whereas others may have little or no significant effect on the dopamine system and may still cause NMS).

3. Introduce delayed fever onset or, more rarely, no fever at all.

4. Either add to criterion B (10) other laboratory findings (serum aldolase, serum myoglobin, myoglobinuria and specific CPK levels), or remove elevated CPK altogether.

5. Either introduce "atypical neuroleptic syndrome" as a separate diagnostic entity or incorporate their atypical features into the existing criteria as a separate criterion.

\section{TREATMENT AND MANAGEMENT OF NMS}

The first and most critical step in treatment is to identify and promptly discontinue the causative agent. In another clinical scenario, restarting any recently stopped dopamine agonists may be an appropriate intervention. Thus, besides medication assessment, it mandates that psychiatrists be cognizant of the early clinical signs of the syndrome. Supportive care includes monitoring vital signs, intravenous fluid replacement, provision of cooling blankets and administration of antipyretics. Support of cardiac, respiratory and renal functions monitoring for complications and preventing them is also part of this step. If improvement in symptoms is not seen within the first few days or the symptoms are severe enough to warrant additional interventions, pharmacotherapy is the next step (75). Sakkas et al $(76,77)$ failed to find an effect of drug treatment on the duration of NMS, but demonstrated a highly significant effect on the mortality rate, which declined from 
$21.10 \%$ in patients receiving only supportive therapy to $9.7 \%$ in patients receiving specific drug treatment.

Bromocriptine is an ergot alkaloid, which acts as a partial but direct agonist at certain dopamine receptors in the brain. It is effective in almost $80 \%$ of cases of NMS $(19,43)$. It is given either per os (p.o) or via a nasogastric tube at a dose of $5 \mathrm{mg}$ p.o t.i.d., increased daily by $5 \mathrm{mg}$ increments until positive response, up to a max of $60 \mathrm{mg} /$ day. Bromocriptine should be continued for 10 days and then gradually withdrawn. During this phase, the patient should be carefully monitored for relapse of NMS. The common side effects include nausea, hypotension and delirium. Exacerbation of underlying psychotic illness may also occur. Sakkas and colleagues also found that bromocriptine significantly reduced mortality from $21 \%$ to $10.1 \%$ when combined with other drugs, and to $7.8 \%$ when used alone $(76,77)$. In contrast, Rosenberg and Green reported that bromocriptine significantly shortened the time to recovery compared to supportive treatment alone (78). Amantadine has also been used, though less frequently in the pharmacological management of NMS. It enhances Dopaminergic neurotransmission, which may involve increased synthesis and/or release of dopamine and inhibition of the reuptake of dopamine. It is also found to be effective in $80 \%$ of patients and reduces death rate to less than $6 \%$ $(76,77)$. Side effects include agitation, insomnia, hallucinations and livedo reticularis.

Levodopa (L-dopa) a dopamine precursor, is effective in about $50 \%$ of the reported cases. It is used less often than either bromocriptine or amantadine. Side effect profile is typical of a dopaminergic agent. If the patient cannot tolerate bromocriptine or is unable to take oral medications, dantrolene, either oral or the more effective parenteral form, can be used. Dantrolene, a hydantoin, dissociates excitation/contraction coupling in the skeletal muscle by interfering with the release of $\mathrm{Ca}^{2+}$ from the sarcoplasmic reticulum. Dantrolene is also used as a muscle relaxant in various conditions. The usual intravenous dose is 1-3 $\mathrm{mg} / \mathrm{kg}$ body wt. q.i.d. The dose is gradually increased until a positive response is achieved. Side effects include hepatotoxicity, excessive muscle relaxation or cardio-respiratory depression when combined with calcium-channel blockers. Yamawaki et al $(19,43)$ reported positive effects in $74.5 \%$ of cases treated in Japan. Dantrolene can be administered together with a dopamine agonist. However, various studies either cast doubt, or point to the possibility that these agents combined may actually retard the course of improvement of NMS (7577,79).

Other drugs include benzodiazepines, which may be useful in controlling agitation or reversing catatonia, although enduring responses have not been achieved. Anticholinergic medications are not helpful and may worsen the condition by further impairing centrally-mediated temperature regulation. Carbamazepine is controversial. There are reports for and against its use in NMS and/or with neuroleptics $(80,81)$. Other drugs found to be effective in isolated reports include lisuride, nitroprusside, other muscle relaxants, and calcium 
channel blockers (9). There are some reports of using vitamins E and B6 in the treatment of NMS (82).

\section{Electroconvulsive Therapy}

Electroconvulsive therapy (ECT) is another treatment option in NMS, presumably because it increases dopamine turnover in the brain (83). However, virtually every neurotransmitter system is affected by ECT. Also, changes have been observed in second messenger systems after ECT. The exact mechanisms by which these neurochemical changes favorably affect the course of NMS is still not clear. There are some reports of a favorable response to ECT in up to $83 \%$ of the cases (84). ECT therapy is particularly indicated when there is difficulty in distinguishing between NMS and lethal catatonia and when there seems to be a significant risk of recurrence of NMS on restarting neuroleptics (85). There are also some very recent reports from Japan, according to which the symptoms of NMS resolved by the third or fourth session of ECT and the mean time from the initial ECT to complete resolution was 6.0 days. In this study, no side effects from ECT were observed (86).

\section{Complications and Prognosis}

Careful monitoring for complications, like aspiration pneumonia, thromboembolism and renal failure is of paramount importance. The most common medical complications leading to morbidity and mortality are respiratory failure and renal failure. Shalev and co-workers reported that myoglobinemia and renal failure are the best predictors of mortality in NMS; the presence of either condition presages a $50 \%$ mortality risk (41). Rhabdomyolysis, severe dehydration and electrolyte imbalance have all been implicated as possible causes of acute renal failure. Fluid and electrolyte replacement and close monitoring of the renal functions are crucial preventive measures to avoid this very important and serious complication. Other rare complications include development of contractures, myocardial infarction, cardiac arrhythmia and disseminated intravascular coagulation (DIC). A rare case of dementia has also been reported as a complication of NMS (87). Contractures may be severe enough to require surgical correction and thus prevention should include early and proactive institution of physical therapy $(88,89)$. Prevention of thromboembolism and related complications is highly controversial. Recommendations range from no prophylaxis to low-dose heparin in usually immobile patients, to complete anticoagulation during immobility. Both acute cardiac failure and serious cardiac arrhythmia have been reported during an episode of NMS (90). Rare hypokinetic and hyperkinetic arrhythmia may occur which are usually refractory to drug treatment (91). Mortality has fallen from $75 \%$ in 1960 's to less than $10 \%$ in 1990 's. The decline presumably reflects not only greater awareness of the syndrome, but also the increasing use of SDAs, and is likely to continue. 
Restarting Therapy After NMS Resolution

Psychotic patients who experience NMS often continue to be psychotic during and after the attack, posing a treatment dilemma. Up until mid-1990's, the general trend was to start a low potency antipsychotic agent cautiously after 14 days of the resolution of symptoms of NMS or 28 days in patients who received depot preparation. However, with the advent of atypical antipsychotics, the practice of choosing SDA's over low potency antipsychotics is becoming increasingly common. A recently published paper reported (92) the responses of 57 leading experts in the field to the following question: a patient with Chronic Schizophrenia developed NMS during treatment with a high potency conventional antipsychotic - the conventional antipsychotic was discontinued and the patient recovered from the episode of NMS - the patient is now becoming psychotic again-please rate the following treatment strategies for this patient. (The choices include all the available SDA's lower potency conventional antipsychotics as a group; midpotency conventional antipsychotics as a group and resume treatment with the original conventional antipsychotic at a lower dose). The responses were:

$77 \%$ recommended Olanzapine as first line.

73\% recommended Clozapine as first line.

$63 \%$ recommended Quetiapine as first line.

$55 \%$ recommended both Ziprasidone and Risperidone as low first line.

$20 \%$ recommended mid potency Conventional Antipsychotic as low $2^{\text {nd }}$ line $7 \%$ recommended mid potency Antipsychotic as low $2^{\text {nd }}$ line.

$0 \%$ recommended resuming treatment with the original Conventional Antipsychotic at a lower dose.

\section{CONCLUSION}

Though our understanding of this comparatively recent entity known as neuroleptic malignant syndrome has considerably increased, it is still far from complete. At present, no pathognomonic "litmus test" exists for the entity. The current research diagnostic criteria proposed by DSM-IV-TR has little or no advantage over the preexisting-mainly because of the poorly understood pathophysiological mechanisms underlying the syndrome. Prevention is an essential part of managing this heterogeneous condition.

The lowest doses of neuroleptics are recommended. For reasons not entirely clear, the mortality rate is decreasing. Many factors may be responsible for the decline. The basis of treatment for NMS is early recognition and diagnosis followed by cessation of causative agents and provision of supportive care. However, in rapidly deteriorating, catastrophic varieties or when there is no response to the initial measures, psychopharmacological and more advanced interventions are warranted. After resolution of symptoms, re-challenge may be considered, ideally with SDA's, but with caution. 


\section{REFERENCES}

1. Delay J, Pichot P, Lemperiere T, Elissalde B, et al. Un neuroleptique majeur nonpnenothiazine et non-reserpinique, L'haloperidol dans le traitment des psychoses. Ann Med Psychol 1960; 118: 145-152.

2. Delay J, Deniker P. Drug induced extrapyramidal syndrome. In: Handbook of Clinical Neurology: Diseases of the Basal Ganglia, vol. 6, Vinken PJ, Brwyn GW eds. New York: Elsevier/North Holand, 1968, pp. 248-266.

3. Farrier A. Le syndrome malin existe-t-il? Lille Medical 1965; 10: 404-413.

4. Bourgeois M, Tignol J, Henry Pneur. Syndrome malin et morts subite au covrs des traitments par Neuroleptiques simple et retard. Ann Med Psychol (Paris). 1971; 2: 729-746.

5. Itoh H, Ohtsuka N, Ogita K, et al. Malignant neuroleptic syndrome. Folia Psychiatrica et Neurologica Japonica 1977; 31: 565-576.

6. Meltzer Hy. Rigidity, Hyperpyrexia and Coma following Fluphenazine enanthate. Psychopharmacologica, 1973; 29: 337-346.

7. Weinberger D, Kelley M. Catatonia and the malignant syndrome: a possible complication of neuroleptic administration. J Nerv Ment Dis 1977; 165: 263-268.

8. Caroff SN. The neuroleptic malignant syndrome. J Clin Psychiatry 1980; 41: 79-83.

9. Lazarus A, Mann SC, Caroff SN. The Neuroleptic Malignant syndrome and related conditions. Washington, DC, American Psychiatric Press Inc, 1989.

10. Tasman A, Kay J, Lieberman JA. In Psychiatry-VOL2-edition. Chapter 69. Philadelphia, W.B. Saunders Company, 1997.

11. Rosebush PI, Stewart TD, Glenberg AJ. Twenty neuroleptic rechallenges after neuroleptic malignant syndrome in 15 patients. J Clin Psychiatry 1989; 50: 295-298.

12. Keck PE, Pope HG, Cohen BM, et al. Risk factors for neuroleptic malignant syndrome. Arch Gen Psychiatry 1989; 46: 914-918.

13. Deuschl G, Oepen G, Hermle L, et al. Neuroleptic Malignant Syndrome: Observation on altereted Consciousness. Pharmacopsychiat 1987; 20: 168-170.

14. Otani K, Horvchi M, Kondo T, et al. Is the predisposition to neuroleptic malignant syndrome genetically transmitted? Br J Psychiatry 1991; 158: 850-853.

15. Kawanishi C, Hanihara T, Shimoda Y, et al. Lack of association between NMS and polymorphisms in the 5-HT1A and 5-HT2A receptor genes. Am J Psychiatry 1998 Sep; 155(9): 1275-1277.

16. Iwaheshi K, Yoshihara E, Nakamura K, et al. CYP 2D6 Hhal genotype and the neuroleptic malignant syndrome. Neuropsychobiology 1999; 39(1): 33-37.

17. Rosebush P, Stewat T. A prospective analysis of 24 episodes of neuroleptic malignant syndrome. An J Psychiatry 1989; 146: 717-725.

18. White DAG, Robins AH. Catatonia: Harbinger of the neuroleptic malignant syndrome. Br J Psychiatry 1991; 158: 419-421.

19. Yamawak S, Yano E, Uchitomi Y. Analysis of 497 cases of neuroleptic malignant syndrome in Japan. Hiroshima Journal of Anesthesia 1990; 26: 35-44.

20. Berardi D, Amore M, Keck PE Jr, et al. Clinical and pharmacological risk factor for neuroleptic malignant syndrome: a case control study. Biol Psychiatry 1998 Oct 15; 44(8): $748-754$.

21. Caroff SN, Mann SC. Neuroleptic malignant syndrome. Psychopharmacol Bull 1998; 24: 25-29. 
22. Peterson SE, Myers KM, McClellan J, et al. Neuroleptic malignant syndrome: three adolescents with complicated cases. J Child Adolescence 1995; 5: 139-149.

23. Silva RR, Munoz DM, Alpert M, et al. Neuroleptic Malignant Syndrome in Children and Adolescents. J Am ACAD CHILD ADOLESGENCE. Psychiatry 1999 Feb; 38(2): 187-194.

24. Shalev A, Mumitz H. The neuroleptic malignant syndrome: Agent and Host interaction. Acta Psychiatr Scand 1986; 73: 337-347.

25. Hasan S, Buckley P. Novel antipsychotics and the neuroleptic malignant syndrome: a review and critique. Am J Psychiatry 1998 Aug; 155(8): 1113-1116.

26. Bajjoka I, Patel T, O’Sullivan T. Risperdone-induced Neuroleptic Malignant Syndrome. Ann Emerg Med 1997 Nov; 30(5): 698-700.

27. Moltz DA, Coeytaux RR. Case report: possible Neuroleptic Malignant Syndrome associated with Olanzapine. J Clin Psychopharmacol 1998 Dec; 18(6): 485-486.

28. Burkhard PR, Vingerhoets FJ, Alberque C, et al. Olanzapine-induced Neuroleptic Malignant Syndrome. Arch Gen Psychiatry. 1999 Jan; 56: 101-102.

29. Kara Gianis JL, Phillips LG, Hogan KP, et al. Glozapine associated Neuroleptic: two new cases and a review of the literature. Ann Pharmacother 1999 May; 33(5): 623-630.

30. Fricchione GI. Neuroleptic catatonia and its relationship to psychogenic catatonia. Biol Psychiatry 1985; 20: 304-313.

31. Bristow MF, Kohen D. Neuroleptic Malignant Syndrome. BMJ 1994 Jan 15; 308: 200.

32. Kaufmann CA, Wyatt RJ. Neuroleptic Malignant Syndrome. In: Meltzer Hy, ed. Psychopharmacology: The Third Generation of progress. New York, NY: Raven press pubs: 1987: 1421-1430.

33. Mann SC, Caroff SN, Lazarus A. Pathogenesis of NMS. Psychiatric Annals 21-3/March 1991: 175-180.

34. Caroll BT. The Universal Field Hypothesis of Catatonia and Neuroleptic Malignant Syndrome. CNS Spectrums. The International Journal of Neuropsychiatric Medicine. Volume 5- Number 7. July 2000: 26-33.

35. Gurrera RJ. Sympathoadrenal hyperactivity and the etiology of Neuroleptic Malignant Syndrome. Am J Psychiatry 1999 Feb; 156(2): 169-180.

36. Mann SC, Caroff SN, Bleier HR, et al. Lethal Catatonia. Am J Psychiatry 1986; 143: 1374-1381.

37. Horn E, Lach B, Lapierre Y, et al. Hypothalamic pathology in the Neuroleptic Malignant Syndrome. Am J Psychiatry 1988; 145: 617-620.

38. Jones EM, Dawson A. Neuroleptic Malignant Syndrome: A case report with post mortem brain and muscle pathology. J Neurol Neurosurg Psychiatry 1989; 52: 1006-1009.

39. Kish SJ, Kleinert R, Minauf M, et al. Brain neurotransmitter changes in three patients who had a fatal hyperthermia syndrome. Am J Psychiatry 1990; 147: 1358-1363.

40. Lee S, Merriam A, Kim TS, et al. Cerebellar degeneration in Neuroleptic Malignant Syndrome. Neuropathological findings and review of the literature concerning heat related nervous system injury. J Neurol Neurosurg Psychiatry 1989; 52: 387-391.

41. Shalev A, Munitz H. Mortality from Neuroleptic Malignant Syndrome. J Clin Psychiatry 1989; 50: $18-25$.

42. Caroff SN, Mann SC, Lazarus A, et al. Neuroleptic Malignant Syndrome: Diagnostic issues. Psychiatric Annals 1991; 21: 130-147.

43. Yamawaki S, Yano E, Terakawa N, et al. On the results of a nationwide survey on 
Neuroleptic Malignant Syndrome. Hiroshima Journal of Anesthesia 1988; 24(suppl 19): $52-67$.

44. Rosebush PI, Mazurek MF. Serum iron and neuroleptic Malignant Lancet 1991; 338: 149-151.

45. Denborough MA, Lovell RRH. Anesthetic deaths in a family (letter). Lancet 1960; 2: 45.

46. Britt BA. Hereditary and epidemiological aspects of malignant hyperthermia. In: Nadia Felipa MA, Gottman S, Khembaba HJ (eds.): Malignant hyperthermia: current concepts. 1989, pp. 19-40.

47. Britt BA, Kalow W. Malignant hyperthermia: A statistical review. Can Anesth Soc J 1970; 17: 293-315.

48. Nelson TE, Flewellen EH. The malignant hyperthermia syndrome. NEJM 1983; 309: 416-418.

49. Paasuke RT, Brownell AK. Serum creatinine kinase level as a screening for susceptibility to malignant hyperthermia. JAMA 1986; 255: 769-774.

50. Browne B, Linter S. Monoamine oxidase inhibitors and narcotic analgesics. A critical review of the implications for treatment. Br J Psychiatry 1987; 151: 210-212.

51. Nierenberg DW, Semprebon M. The central nervous system serotonin syndrome. Clin Pharmacol Ther 1993; 53: 84-88.

52. Goldberg RJ, Huk M. Serotonin syndrome from trazodone and Buspirone (letter). Psychosomatics 1992; 33: 235-236.

53. Leppin RI, Auchincloss EL. Treatment of the serotonin syndrome with cyproheptadine (letter). N Engl J Med 1994; 331: 1021-1022.

54. Muly EC, McDonald W, Staffens D, Book S. Serotonin syndrome produced by a combination of fluoxetine and lithium (letter). Am J Psychiatry 1993; 150: 1565.

55. Somdyk R. L-dopa induced 'serotonin syndrome' in a parkinsonian patient on bromocriptine (letter). J Clin Psychopharmacol 1986; 6: 194-195.

56. Lieberman JA, Kane JM, Reife R. Neuromuscular effects of monoamine oxidase inhibitors. Adv Neurol 1986; 43: 231-249.

57. Fricchione G, Bush G, Fosdar M, Francis et al. Recognition and treatment of catatonic syndrome. Journal of Intensive Care Medicine 1997; 12: 135-147.

58. Reilly JJ, Crave SF, Lloyd JH. Neuroleptic Toxicity Syndromes: a clinical spectrum. Aust NZ J Psychiatry 1991; 25: 499-505.

59. Adityanjee. The myth of elevated serum CPK and Neuroleptic Malignant Syndrome. Br J Psychiatry 1991; 158: 706-707.

60. Lavenson JL, Neuroleptic Malignant Syndrome. Am J Psychiatry 1985; 142: 1137-1145.

61. Pope HG Jr, Keck PE Jr, McElroy SL. Frequency and presentation of neuroleptic malignant syndrome in a large psychiatric hospital. Am J Psychiatry 1986; 143: 1227-1233.

62. Schatzberg AF, Cole JO. Manual of Clinical Psychopharmacology, ed. 2, pp. 126. American Psychiatric Press, Washington, 1991.

63. American Psychiatric Association. Diagnostic and Statistical Manual of Mental Disorders, Fourth Edition, Text Revision. Washington, DC, American Psychiatric Association, 2000.

64. Baker RW, Chengappa KN. Further study of Neuroleptic Malignant Syndrome. Am J Psychiatry 1995 December; 152: 12-1831.

65. Nonino F, Campomoric A. Neuroleptic Malignant Syndrome associated with metaclopropamide. Ann Pharmacother 1999 May; 33(5): 644-645.

66. Park-Matsvmoto YC, Tazawa T. Neuroleptic Malignant Syndrome associated with diphen- 
hydramine and diprophyllin overdose in a depressed patient. J Neurosci 1999 Jan 1; 162(1): 108-109.

67. Assion HJ, Heinemann F, Laux G. Neuroleptic Malignant Syndrome under treatment with antidepressants? A critical review. Eur Arch Psychiatry Clin Neurosci 1998; 248(5): 231-239.

68. Heinemenn F, Assion HJ, Hermes G, et al. Paroxetine induced neuroleptic malignant syndrome. Nervenarzt 1997 Aug; 68(8): 664-666 (language: German).

69. Okamoto K, Umeno M, Takagi H. A case of Neuroleptic Malignant Syndrome caused by an anti-depressant agent, later complicated by respiratory insufficiency and DI. Nippon Naika Gakkai Zasshi 1998 April 10; 87(4): 727-729 (language: Jpn).

70. Ehara H, Maegaki Y, Takeshitu K. Neuroleptic Malignant Syndrome and methylphenidate. Pediatr Neurol 1998 Oct; 19(4): 299-301.

71. Wetli CV, Mash D, Karch SB. Cocaine-associated agitated delirium and the Neuroleptic Malignant Syndrome. Am J Emery Med 1996 Jul; I4(4): 425-428.

72. Demirkiran M, Jankovic J, Dean JM. Ecstasy intoxication: an overlap between serotonin syndrome and neuroleptic malignant syndrome. Clin Neuropharmacol 1996 Apr; 19(2): 157-164.

73. Marcus EL, Vass A, Zislin J. Marked elevation of serum creatine kinase associated with Olanzapine therapy. Ann Pharmacother 1999 Jun; 33(6): 697-700.

74. Blumersohn R, Yoran-Hegesh R, Golubchik P. Elevated serum creatine kinase activity in adolescent psychiatric inpatients on admission. Int Clin Psychopharmacol 1998 Nov; 13(6): 269-272.

75. Gelenberg AJ. The best treatment for NMS: (a) dantrolene, (b) bromocriptine, (c) combination, (d) none of the above. Biol Ther Psychiatry 1992; 15: 13-16.

76. Sakkas P, Davis JM, Hua J, et al. Pharmacotherapy of neuroleptic malignant syndrome. Psychiatric Annals 1991; 21: 157-164.

77. Sakkas P, Davis JM, Janicak PG, et al. Drug treatment of the neuroleptic malignant syndrome. Psychopharmacol Bull 1991; 27: 381-384.

78. Rosenberg MR, Green M. Neuroleptic Malignant Syndrome: Review of response to therapy. Arch Intern Med 1989; 149: 1927-1931.

79. Rosebush PI, Stewart T, Mazurek MF. The treatment of neuroleptic malignant syndrome: Are dantrolene and bromocriptine useful adjuvants to supportive care? Br J Psychiatry 1999; 159: 709-712.

80. Nisijima K, Kusakabe Y, Ohtuka K, Ishiguro T, et al. Addition of carbamazepine to long term treatment with neuroleptics may induce neuroleptic malignant syndrome. Biol Psychiatry 1998 Nov 1; 44(9): 930-931.

81. Terao T. Carbamazapine in the treatment of neuroleptic malignant syndrome. Biol Psychiatry 1999 Feb 1; 45(3): 381-382.

82. Dursun S, et al. High dose Vit E plus B6 treatment of resperidone related neuroleptic malignant syndrome. Journal of Psychopharmacology 1998; 12: 220-221. From Dalhousie University, Halifax, N.S. Canada.

83. Pearlman CA. Neuroleptic malignant syndrome: A review of the literature. J Clin Psychopharmacol 1986; 6: 257-273.

84. Davis JM, Janicak PG, Sakkas P, et al. Electroconvulsive therapy in the treatment of the neuroleptic malignant syndrome. Convulsive Therapy 1991; 7: 111-120. 
85. Addonizio G, Susman VL, Roth SD. Neuroleptic malignant syndrome: Review and analysis of 115 cases. Biol Psychiatry 1987; 22: 1004-1020.

86. Nisijima K, Ishiguro T. Electroconvulsive therapy for the treatment of neuroleptic malignant syndrome with psychotic symptoms: a report of five cases. J ECT 1999 Jun; 15(2): $158-163$.

87. Welch JB. Dementia as a cause of neuroleptic malignant syndrome. Am J Psychiatry 1993 Oct; 150(10): 1561-1562.

88. Craddock B, Craddock N. Contractures in Neuroleptic Malignant Syndrome. Am J Psychiatry 1997 March; 154(3): 436.

89. Black KJ, Racette B, Perlmutter JS. Preventing contractures (correction of contractions) in neuroleptic malignant syndrome and dystonia. Am J Psychiatry 1998 Sep; 155(9): $1298-1299$.

90. Enaissa ML, Bekka R, Band FJ. Acute cardiac failure in a case of rapidly lethal neuroleptic malignant syndrome. Intensive Care Med 1998 Jan; 24(1): 86.

91. Cordioli E, Pizzi C, Tondini C. Cardiac arrhythmias associated with malignant neuroleptic syndrome: description of 2 clinical cases. G Ital Cardiol 1997 Nov; 27(11): 1164-1168.

92. McEvoy JP, Scheifler PL, Frances A. The expert consensus. Guideline series: Treatment of Schizophrenia 1999. J Clin Psychiatry 1999; 60(suppl 11): 49. 